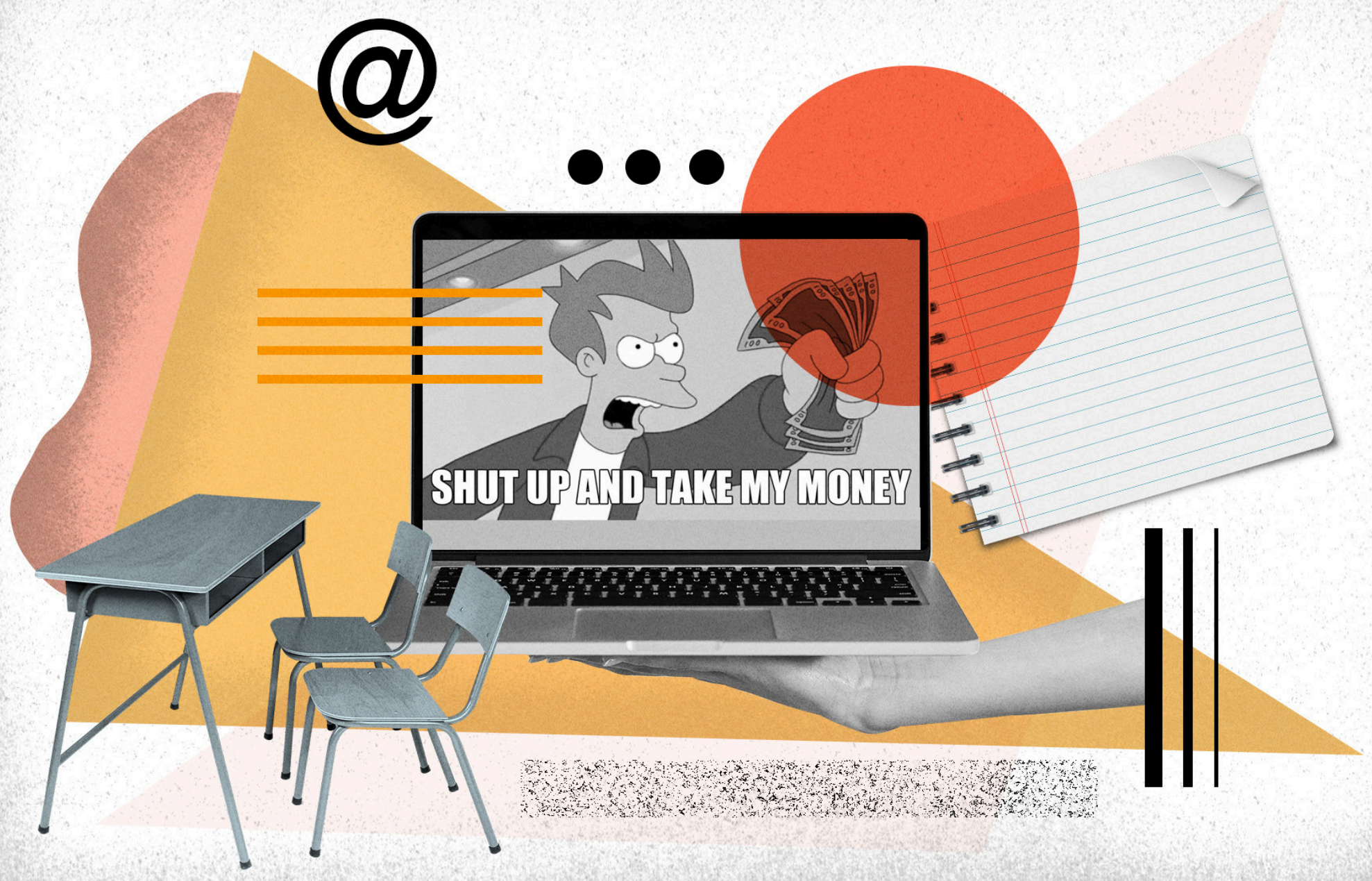

\title{
Meme educativo: experiencia para una pedagogía de la cultura visual
}

EDUCATIONAL MEME: EXPERIENCE FOR A PEDAGOGY OF VISUAL CULTURE MEME EDUCACIONAL: EXPERIÊNCIA PARA UMA PEDAGOGIA DA CULTURA VISUAL

\section{Rennier Estefan Ligarretto Feo}




\section{Rennier Estefan Ligarretto $\mathrm{Feo}^{1}$}

- Mestre em ciencias da educacao, Universidade Nova De Lisboa. Profesor Investigador, Facultad de Educación, Pontificia Universidad Javeriana. ORCID: https://orcid.org/0000-0002-8666-8284; correo electrónico: rennierligarretto@hotmail.com

\section{Citar artículo como:}

Ligarretto, R. (2020, Julio-Diciembre). Meme educativo: experiencia para una pedagogía de la cultura visual. Revista Educación y Ciudad, No. 39, pp 131-145. //doi.org/10.36737/01230425.n39.2020.2341

DOI: https://doi.org/10.36737/01230425.n39.2020.2341

Fecha de recepción: 2 de febrero de 2020 / Fecha de aprobación: 1 de julio de 2020

\section{Resumen}

El presente artículo expone los resultados de una estrategia educativa cuyo objeto es mediar la práctica docente a partir del uso, creación e interpretación de memes, para favorecer los procesos de lectura, análisis y síntesis de contenidos de asignaturas en la educación superior. Para ello, se aborda la cultura visual y la cibercultura como nuevas alternativas multimediales para incorporar al meme. El método empleado presenta un enfoque mixto de corte exploratorio; entre los resultados se evidencia una tendencia positiva frente a la generación de hábitos de lectura, participación y comprensión de contenidos.

Palabras clave: Meme, cultura visual, lenguaje visual, TIC, cibercultura.

\section{Abstract}

This article presents the results of an educational strategy that aims to mediate teaching practice from the use, creation and interpretation of memes to favor the processes of reading, analysis and synthesis of subject content in higher education. For this, visual culture and cyberculture are addressed as new multimedia alternatives to incorporate into the meme. The method used presents a mixed exploratory approach; The results show a positive trend in relation to generating reading habits, participation and understanding of content.

Keywords: Meme, Visual Culture, Visual Language, ICT, Cyberculture.

\section{Resumo}

Este artigo apresenta os resultados de uma estratégia educacional que visa mediar a prática de ensino por meio do uso, criação e interpretação de memes para favorecer os processos de leitura, análise e síntese do conteúdo da disciplina no ensino superior. Para isso, a cultura visual e a cibercultura são abordadas como novas alternativas multimídia a serem incorporadas ao meme. $\mathrm{O}$ método utilizado apresenta uma abordagem exploratória mista; Os resultados mostram uma tendência positiva em relação à geração de hábitos de leitura, participação e compreensão do conteúdo.

Palavras-chave: Meme, Cultura Visual, Linguagem Visual, TIC, Cibercultura. 


\section{Introducción}

D esde la irrupción de Internet en la década de los noventa, la constante evolución tecnológica parece cumplir los postulados de la ley de Moore, cuando indicaba que los transistores y circuitos integrados duplicarían las funciones y beneficios de sus antecesores en periodos de dos a tres años. Hoy, 50 años después de la invención del microchip, la velocidad de procesamiento y los dispositivos inteligentes deben ser interpretados como artefactos de la cultura que transitan de medios análogos a contextos digitales.

En el contexto educativo, Internet, como principal desarrollo tecnológico, ha evolucionado (Web 1.0, 2.0 y 3.0), para potenciar el trabajo colaborativo y autónomo en la enseñanza; sin embargo, la velocidad en los cambios y transformaciones en las dinámicas sociales y culturales, particularmente el uso de redes sociales y la sobreexposición mediática, vuelcan la mirada frente al uso de la imagen y su implicación en contextos sociales y educativos.

En tal escenario, la sociedad de la información y el conocimiento, como expresión de cambios sociales, culturales, económicos, políticos $\mathrm{y}$ educativos, atravesados por el uso de Tecnologías de la Información y la comunicación (TIC), es el espacio para reflexionar sobre la didáctica en el proceso de enseñanza y aprendizaje, pues, como señaló Pscitelli "El reinado de la imagen se ha vuelto omnipresente no solo como vehículo de comunicación, sino, sobre todo, de creación de sentido" (2005, p.13). Esta transformación se ha dado de manera progresiva en la sociedad y ha permeado positiva y negativamente las dimensiones sociales y educativas.
Por un lado, al revisar los índices de lectura en Colombia, expuestos en la Encuesta Nacional de Lectura (DANE, 2017), es posible notar que el promedio nacional es de 5,1 libros leídos por año en cabeceras municipales; por otra parte, la digitalización de la información ha permitido el surgimiento de nuevas formas de lectura, presentes en blogs, Wikis o textos visuales, como posibilidad de fomentarla en las nuevas generaciones. La cultura digital, como expresión de estos cambios, es ejemplo de las interacciones sociales y culturales expuestas en prácticas, hábitos, costumbres y consumos mediados por la imagen y el audiovisual presentes en las denominadas generaciones digitales (Prensky, 2009).

Lo anterior, permite reflexionar acerca de los usos cotidianos de la imagen, en particular del meme, como producto cultural (Dawkins, 1993) que facilita el abordaje de nuevas maneras de trasmitir información y conocimiento, apoyado en rasgos propios del lenguaje visual. En este sentido, algunos autores sostienen que las interacciones del escenario digital están atravesadas por lo "multimedial", como evidencia del crecimiento de la imagen y el video en la cultura global (García y Gertrudix, 2011); lo "transmedia", como narración continua reproducida en diferentes dispositivos y plataformas (Scolari, 2013); y la "remixación", como proceso de convergencia en el cual se reinterpreta, crea, divulga y comparte información y contenidos en el ciberespacio (Ferguson, 2013). Considerando todo ello, cobra sentido reflexionar sobre los usos educativos del meme, comprendiendo su función de reproducción social, para mejorar la lectura y análisis de textos en la educación superior. 


\section{La cultura visual como escenario para repensar la enseñanza}

En tanto fenómeno sociocultural, la cultura visual puede ser abordada desde distintos campos de conocimiento como modelo explicativo de la cultura; para ello, se debe partir de la propia idea de cultura, de manera que sea posible derivar su interpretación y distinción desde lo visual. La noción en este estudio comprende que la cultura puede ser definida a través de los usos sociales compartidos, que permiten interpretar los fenómenos del mundo (Hall, 1997); por tanto, al momento de trabajar existen distintas dimensiones de uso y significado de la cultura, pues, como afirma Campbell, ella es una: "Totalidad compleja que abarca al conocimiento, las creencias, el arte, la moral, la ley, las costumbres y cualquier otra habilidad y hábitos adquiridos por el hombre como miembro de la sociedad" (2000, p. 31).

Así, es posible reconocer el lugar de acción de la comunicación y la educación presentes en la cultura visual. La "educomunicación", como campo del saber, desdibuja la frontera que dividía a la educación de la comunicación, entendiéndolas como sistemas aislados de la sociedad que convergen en el uso del lenguaje como medio para ejercer sus funciones sociales. Desde esta perspectiva, Kaplún (2014) afirma que la creación de ecosistemas comunicativos, que lleven a la acción procesos de enseñanza y aprendizaje, debe considerar acciones para su propio funcionamiento; opinión compartida por Soares (2011) al momento de definir la educomunicación como un "conjunto de acciones inherentes a la planificación, implementación y evaluación de procesos, programas y productos destinados a crear $y$ fortalecer ecosistemas comunicativos" (p. 44).

Tal definición permite comprender el campo de acción de la cultura visual, el cual puede ejercer su función en un contexto análogo o digital; en tal sentido, los postulados de Levy (2004) en relación con la idea de cibercultura presentan otra dimensión de la expresión de la cultura visual en medios digitales, lo cual hace fundamental la mirada antropológica a la hora de comprender el fenómeno. Al respecto, la American Antrophological Association (1992) afianzó los conceptos de "ciberespacio", "cyborgantropología" y cibercultura como una serie de productos culturales posibles gracias a Internet, constituyendo así una reinterpretación de la imagen y de las redes sociales como medios educomunicativos.

En concordancia con lo anterior, la cultura visual, o cultura de la imagen, es comprendida como espacio de interacción y significado para el análisis de la educomunicación; por ello, resulta conveniente abordarla considerando los postulados de Abril, quien indica que:

\begin{abstract}
La cultura visual es una forma de organización socio histórica de la percepción visual, de la regulación de las funciones de la visión, y de sus usos epistémicos, estéticos, políticos y morales. Es también un modo socialmente organizado de crear, distribuir, e inscribir textos visuales, proceso que implica siempre determinadas tecnologías del hacer-visible técnicas de producción, reproducción y de $\operatorname{archivo~(2013,~p.~35).~}$
\end{abstract}

Lo anterior es el marco para el trabajo de la enseñanza, al permitir repensar su acción en contextos formales o informales, y organizar la práctica docente alrededor del uso de la imagen como artef- 
acto cultural que transita en canales digitales y análogos, enmarcando las didácticas trans-versales a la mediación tecnológica; es desde allí que la experiencia trabajada opta por centrar su atención en el meme, como reproducción de la cultura presente en los escenarios sociales y educativos.

\section{Evolución del Meme: tipologías y tránsitos}

El concepto de Meme tiene su origen en el libro "El Gen Egoísta” de Richard Dawkins (1993), quien se refirió a este elemento definiéndolo como una unidad de transmisión cultural por imitación.

Los rasgos culturales se transmiten de persona a persona, de manera similar a lo que ocurre con los genes o los virus. La evolución cultural puede ser entendida mediante el mismo mecanismo de reproducción, difusión, variación y selección que la evolución biológica [...] el portador de una idea, comportamiento o actitud las comunica de manera directa o indirecta a otra persona, la cual se convierte en portadora, lista para 'infectar' a más personas (Dawkins, 1993, p. 98).

En este sentido, los memes constituyen bloques de construcción elementales para la cultura (Brodie, 1996), en el entendido de que su función busca conservar y replicar la cultura propia de una sociedad; sin embargo, ¿cómo es posible concebir el uso del meme en un contexto digital? Al respecto, es conveniente retomar los postulados de Knobel (2005), quien aborda las implicaciones del meme coincidiendo con otros autores como Adar, Zhang, Adamic y Lukose (2004), o Brodie 1996, al afirmar que:
Dawkins propuso un modelo evolutivo de desarrollo y cambio cultural que se basaba en la replicación de ideas, conocimientos y otra información cultural a través de la imitación y la transferencia. Posteriormente, una variedad de investigadores interesados en la memética, el estudio de los memes, han argumentado que las redes electrónicas, junto con las predilecciones e intereses personales, proporcionan las condici-ones ideales para propagar y dispersar memes (Knoble, 2005, p.1).

Lo anterior también alimentó los postulados de Davison, quien sostiene que: "Un meme de Internet es un fragmento de cualquier unidad de cultura, generalmente un chiste, que va adquiriendo influencia a medida que se va transmitiendo en línea" (2005, p.122). Cuando se reconoce la incidencia de la tecnología en los cambios culturales, cobra sentido el tránsito del concepto Meme por el de “Imeme”, expresión acuñada por José Vélez (2012) para indicar los cambios en la difusión y transmisión de este concepto en un escenario digital, aclarando que la vitalidad del meme está condicionada a su interacción digital, pero no es constitutiva de su creación. Así, respecto de los tipos de "Imeme" utilizados socialmente, es posible rescatar los postulados de Vera (2016), quien les categoriza de la siguiente manera:

- Rage o Paint comic: Realizado con gráficas de programas computacionales, como Paint, de Microsoft, $\mathrm{u}$ otro similar. La sencillez y espontaneidad son características de este tipo de meme, pues emulan gestos faciales y corporales fáciles de interpretar.

- Meme fotografía: Se trata de fotos creadas o sacadas de la realidad, también pueden ser fotogramas extraídos de alguna secuencia de video, exponiendo el rasgo específico de una actitud a partir de los gestos o actos de habla. La relación contextual entre mensaje e imagen garantiza su eficacia. 
- Meme GIF: Por sus siglas en inglés (En español: Formato de intercambio de gráficos), es realizado con una secuencia de fotogramas que pueden ser parte de algún film, serie, comercial, grabación personal, etc. Se pueden montar con otras secuencias de fotograma, dando como resultado una idea más potente desde el punto de vista visual.

- Meme video: Empleados especialmente en las redes sociales por su capacidad de hacerse virales, populares en masa, particularmente en Facebook y Youtube. Los memes video también pueden ser montajes compuestos por diversos fragmentos audiovisuales e implementos compu-tacionales, tales como agregar anteojos oscuros, cigarros, sonrisas, objetos voladores, etc.
Esta clasificación obedece a los recursos digitales dispuestos en la Web 2.0 para crear memes. Su elaboración se concentra en los principios de la cultura Mainstream, como espacio de interacción y reproducción cultural. Junto a ella, otra dimensión destacable es la propuesta por Brodie (1996), quien apela a la noción de fecundidad del meme como una variable fundamental para su difusión en la Web; su argumento es que cuando el meme es transmitido por personas de confianza se genera una mayor apropiación, que se evidencia en una mayor velocidad de divulgación en la red; como ejemplo, el siguiente gráfico resume la tipología propuesta:

Figura 1. Tipología provisional de memes mediados por Internet

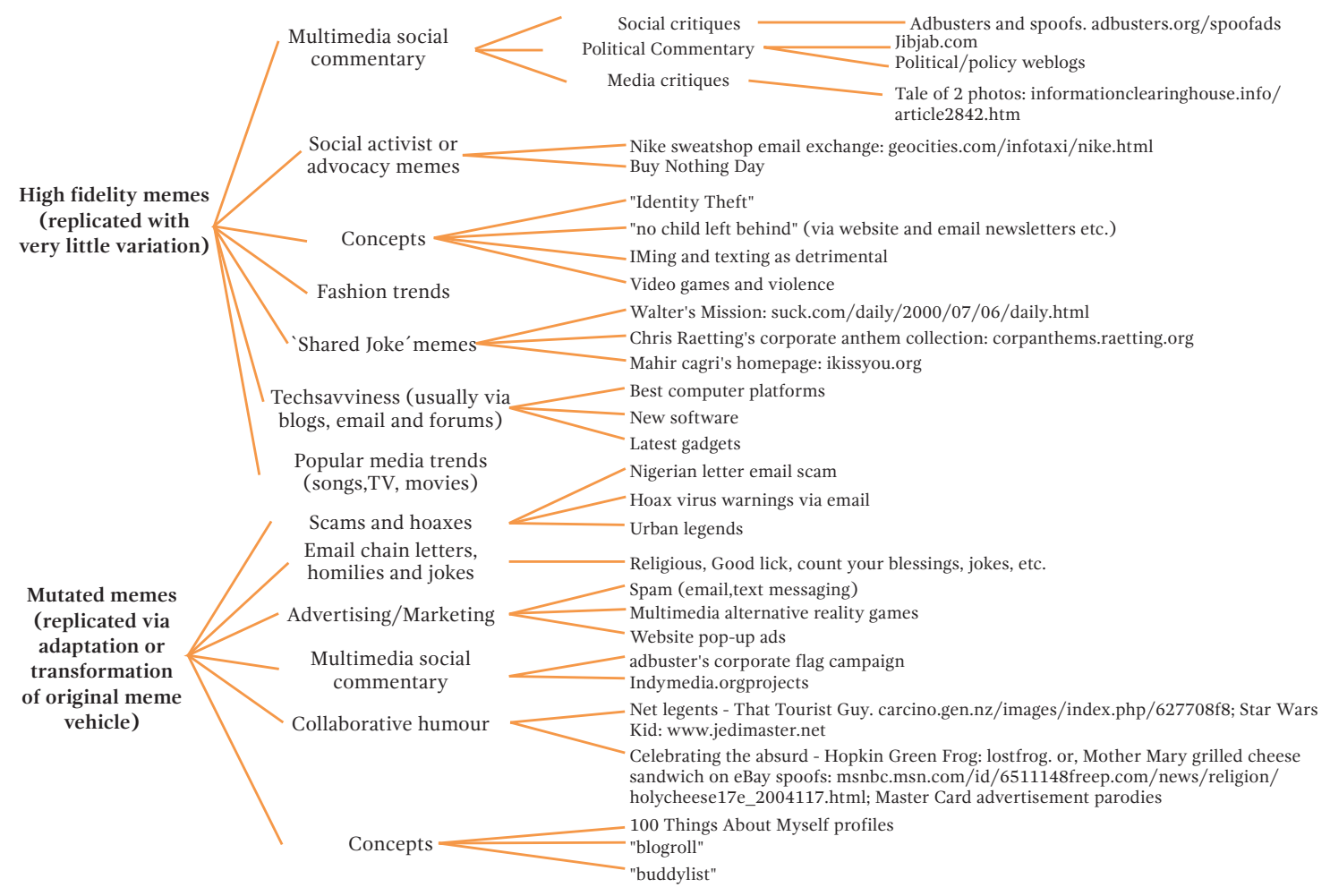

Nota. Fuente: Brodie (1996) 


\section{Conectivismo: un modelo para la enseñanza en la sociedad interconectada}

Para entender la incidencia de la cultura visual, la mediación de la imagen y la transformación propia en el rol docente, es necesario recurrir a apuestas teóricas que fundamenten la concepción de la enseñanza y el aprendizaje a partir de la relación con la tecnología. En tal sentido, el "conectivismo" se da como una teoría para el aprendizaje en la era digital que, a pesar de retomar algunos elementos del constructivismo y el cognitivismo, sostiene el aprendizaje en la red como resultado del diálogo entre conocimientos anteriores y nuevos; aquí cada nodo de la red representa una información o persona que, desde su intención de acceder y generar conocimiento, crea, refuerza y se interconecta con otros nodos para construir colectivamente un conocimiento.

Tal principio favorece el aprendizaje colaborativo y autónomo, al tiempo que facilita generar nuevas conexiones que ayudan a la toma y orientación del aprendizaje; para ello, este último se entiende a partir de la importancia de la auto organización, la cual lleva a que los elementos, presentados caóticamente en la red, adquieran sentido para el estudiante, descartando continuamente información irrelevante o pertinente para el aprendizaje. Desde allí, Siemes (2004), fundador de esta teoría, propone una serie de principios útiles para poner en práctica:

- El aprendizaje y el conocimiento dependen de la diversidad de opiniones.
- El aprendizaje es un proceso de conectar nodos o fuentes de información especializadas.

- El aprendizaje puede residir en dispositivos no humanos.

- La capacidad de saber más es más crítica que aquello que se sabe en un momento dado.

- La alimentación y mantenimiento de las conexiones es necesaria para facilitar el aprendizaje continuo.

- Es clave la habilidad de ver conexiones entre áreas, ideas y conceptos.

- La actualización (conocimiento preciso y actual) es la intención de todas las actividades "conectivistas" de aprendizaje.

- La toma de decisiones es, en sí misma, un proceso de aprendizaje. El acto de escoger qué aprender, y el significado de la información que se recibe, son vistos a través del lente de una realidad cambiante. Una decisión correcta hoy, puede estar equivocada mañana debido a alteraciones en el entorno.

Con este marco, resulta factible relacionar la cultura visual, y el uso de la imagen, como información presente en la red que, para el caso de esta experiencia, centra su atención en el meme como unidad cultural en contextos sociales, culturales, políticos, susceptible de ser empleada en los procesos de enseñanza-aprendizaje. Así, como indica Giesbrecht (2007): "El Conectivismo se presenta como una propuesta pedagógica que proporciona a quienes aprenden la capacidad de conectarse unos a otros a través de las redes sociales, o herramientas colaborativas" (Citado en Campos, 2012, p. 115); perspectiva que permite concebir el conectivismo como plataforma teórica para trabajar unidades culturales presentes en los memes, entendiéndolos como herramienta para potenciar los hábitos de lectura, análisis y síntesis de textos. 


\section{Metodología}

El método empleado desarrolla un enfoque mixto, lo cual implica la presencia de rasgos de corte cualitativo y cuantitativo, respondiendo al carácter exploratorio del estudio; como complemento, se emplea un cuestionario de carácter y una etnografía virtual, buscando abordar un objeto empírico de investigación presente en una cultura, pueblo o sociedad, para describirlo e interpretarlo de acuerdo a lo que el investigador escucha y ve (Guber, 2004). El enfoque visual fundamenta su acción en los objetos simbólicos de la cultura, los cuales se expresan en el ámbito cotidiano, pues son:

Las producciones simbólicas de los hombres y las sociedades que se materializan en objetos, los cuales traducen significaciones concretas en un tiempo determinado y que prevalecen sobre la vida de las personas. No solo interesan los objetos de la cultura material, que pueden ser desde utensilios cotidianos, la arquitectura, los objetos de arte y de uso religioso, sino también la imagen y el sentir del hombre mismo [...]. En este ámbito las propias imágenes de películas y videos también se constituyen en objetos de representación y análisis, puesto que son objetos simbólicos y por lo tanto manifestaciones comunicativas (Rodrigo, 2003, citado en Páramo, 2011, p. 155).

Lo anterior, es acompañado por una perspectiva abductiva que permitió articular las fuentes bibliográficas, la observación participante y el uso de cuestionarios para responder al objetivo principal de la experiencia educativa: El uso e interpretación del meme como herramienta didáctica para mediar la práctica docente $\mathrm{y}$ favorecer los procesos de lectura, análisis y síntesis de contenidos. La población que participó de la experiencia se compuso de estudiantes de la Facultad de Educación de la Pontificia Universidad
Javeriana, sede Bogotá. La estrategia se desarrolló durante el año 2019, abarcando dos (2) semestres de la asignatura "Cibercultura y ciudadanías", con un total de 50 estudiantes. A continuación, se presentan las fases que estructuran el ejercicio.

\section{Primera fase}

Se realizó un ejercicio exploratorio para revisar las fuentes bibliográficas existentes frente al uso de la imagen en la cibercultura, de tal manera que fuese posible definir los temarios principales que desarrollaría la asignatura. A partir de dicha revisión se decidió trabajar la imagen como herramienta para la mediación de la práctica docente, fomentando la creación de memes como una dinámica para la consulta, revisión y análisis de los textos abordados a lo largo de la asignatura. En este proceso, se acordaron las reglas de juego, dinámica y evaluación de la materia, mediante la definición de características específicas para la creación de memes, resumidas en la siguiente estructura: 
Figura 1. Elementos a considerar en la creación de memes

\begin{tabular}{|c|c|}
\hline Estructura & Ejemplo \\
\hline Imagen & 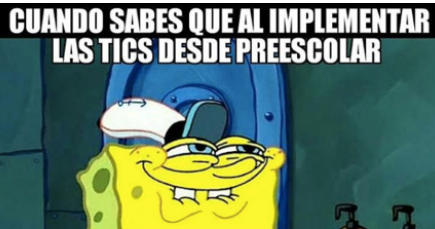 \\
\hline Nombre del estudiante & Claudia Liliana \\
\hline Nombre de la asignatura & Cibercultura y ciudadanías \\
\hline Nombre del texto & $\begin{array}{c}\text { Experiencias de uso de TIC en } \\
\text { la Educación Preescolar } \\
\text { en Venezuela }\end{array}$ \\
\hline Conclusión del texto & $\begin{array}{l}\text { La tecnología integrada al } \\
\text { currículo se presenta como } \\
\text { la propuesta más apropiada } \\
\text { para el uso de la misma en el } \\
\text { nivel de preescolar. Múltiples } \\
\text { reseñas de experiencias de } \\
\text { uso de la tecnología en el } \\
\text { preescolar se refieren a la } \\
\text { consideración de los principios } \\
\text { planteados, en el sentido de } \\
\text { que resaltan la importancia } \\
\text { de incorporar la tecnología } \\
\text { en las aulas preescolares } \\
\text { desde prácticas apropiadas, } \\
\text { donde el computador sea } \\
\text { un componente integral e } \\
\text { inevitable del currículo }\end{array}$ \\
\hline
\end{tabular}

\section{Segunda fase}

Durante esta etapa se desarrollaron las estrategias planteadas para la dinámica de clase, las cuales inician con una revisión de los memes creados, como pretexto para generar escenarios de análisis y debate frente a los temas abordados; con ello en mente, se creó una cuenta en Instagram denominada @claseciberculturayciudadania, con un usuario y clave comunes, de tal forma que todos los estudiantes publicaran en el mismo espacio las reflexiones generadas a partir del análisis y síntesis de los textos.

\section{Tercera fase}

El último momento del trabajo se concentró en la implementación unos cuestionarios con preguntas abiertas y cerradas, diseñadas para reconocer las valoraciones realizadas durante el desarrollo de la asignatura y los aspectos de mejora o motivación presentes en la lectura de textos y creación de memes. Al finalizar, se revisaron todos los memes creados y se otorgó una valoración colaborativa para premiar, según consideraron los estudiantes, al más creativo.

\section{Principales resultados}

Para la presentación de resultados se resaltan los momentos de inicio, desarrollo y cierre de la práctica docente a partir de la experiencia pedagógica implementada. En el inicio del proceso se indagó por los hábitos de lectura de los estudiantes, en relación con las asignaturas que cursan en la universidad.

Nota. Fuente: Elaborado por autor 
Figura 2. Hábitos de lectura

En general de acuerdo a su hábitos de lecutura, indique el promedio de veces que lee los textos asignados previo inicio de una clase

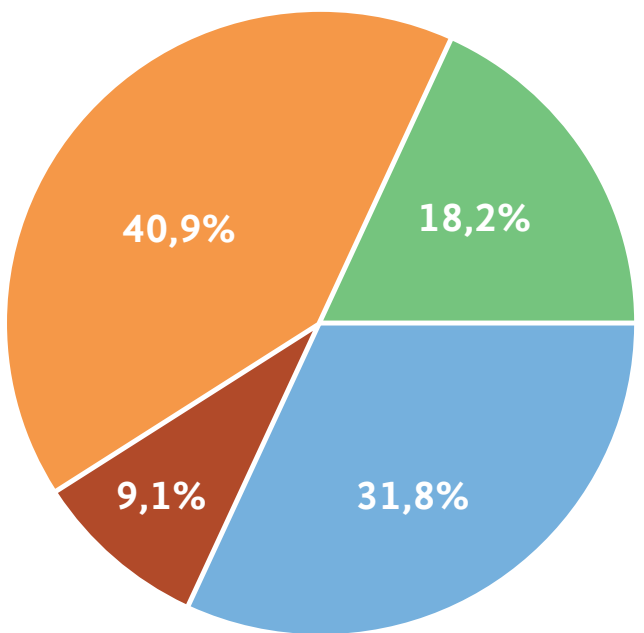

Una vez por semana

Una vez cada quince días

La mitad de las clases

Todas las clases

Nota. Fuente: Elaborado por autor

Los resultados indican que un mayor porcentaje (40,9\%) de estudiantes solo lee la mitad de los textos asignados a sus clases, lo cual se constituye como reto docente, para establecer los motivos e implicaciones de asistir a ellas sin información sobre los contenidos a trabajar, distinta de la provista por el docente durante el desarrollo de la asignatura. Sumado a ello, al indagar por el consumo de memes en Internet y el espacio de tiempo destinado a dicha actividad, se encontró lo siguiente.
Figura 3. Consumo de memes

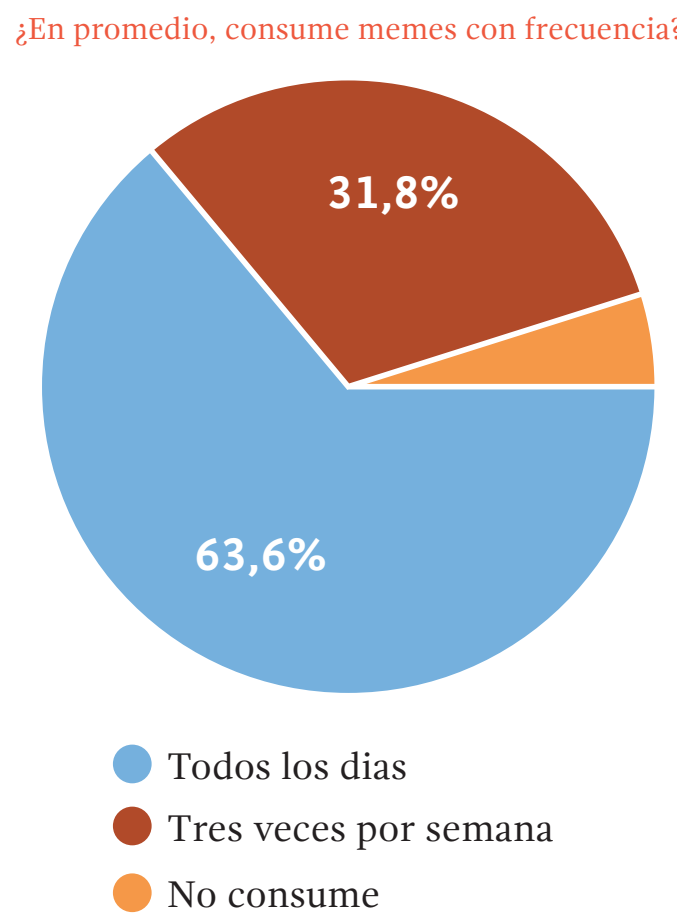

Nota. Fuente: Elaborado por autor

De acuerdo a los resultados, 63,3\% de los estudiantes consume memes todos los días, mientras que solo el $31,8 \%$ lo hace 3 veces por semana; dichos resultados destacan la importancia de trabajar desde elementos comunes, presentes en la cotidianidad de las redes sociales, pero utilizándolos con una intencionalidad pedagógica específica, encaminada a la mejora de la lectura en contextos de educación superior.

Finalmente, al contrastar los hábitos de lectura y consumo mediático, partiendo de la experiencia pedagógica desarrollada, los estudiantes valoraron el uso del meme como herramienta para mejorar la lectura y análisis de los textos utilizados, específi- 
camente desde la pregunta: ¿Considera que el uso del meme incentivó el ejercicio de lectura y análisis de los textos de la asignatura?

Figura 4. Nube de palabras que representa el índice de respuesta frente a la pregunta: ¿Considera que el uso del meme incentivó el ejercicio de lectura y análisis de los textos de la asignatura?

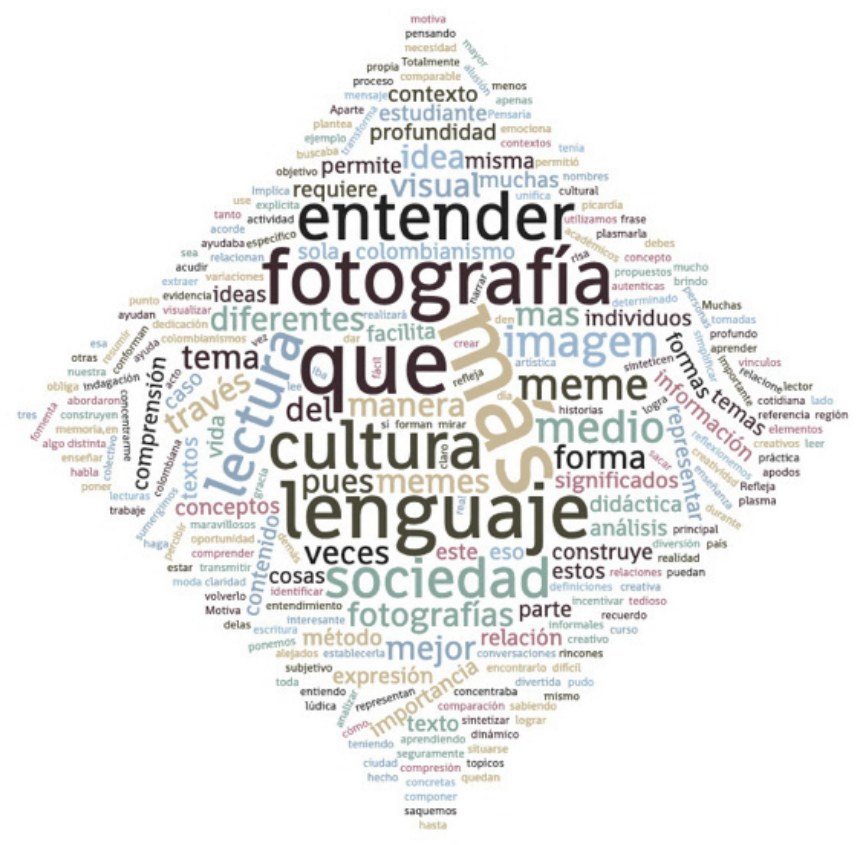

Nota. Fuente: Elaborado por autor

La nube de palabras (Figura 4) permite reconocer la frecuencia de conceptos empleados por los estudiantes para analizar los beneficios del uso de memes, desde la idea de incentivar la lectura y análisis de textual; conceptos como Lenguaje, Entender, Cultura, Fotografía, Lectura y Meme, se destacan por la frecuencia en que fueron asociados al desarrollo de la estrategia pedagógica.
Por su parte, la revisión de la cuenta creada permitió reportar un total de 244 publicaciones realizadas de acuerdo con los elementos descritos en la fase anterior; desde allí, se indagó por las habilidades de los estudiantes, asociadas a la creación de memes, evidenciando que un $50 \%$ de ellos consideró que el ejercicio le permitió trabajar la creatividad, mientras un 22,7\% manifestó que el trabajo llevó a mejorar la capacidad de síntesis frente a la lectura y comprensión de textos, y un 13,6\% expresó que funciona para analizar y dominar el tema.

Figura 5. Fomento de habilidades

De las siguientes habilidades ¿̨cuál considera que aportó más para el desarrollo de la asignatura La creación de memes?

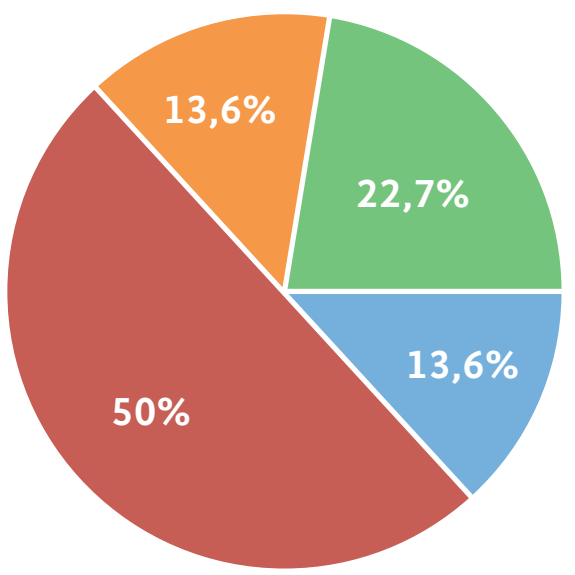

Dominio del tema

Creatividad

Capacidad de análisis

Síntesis

Nota. Fuente: Elaborado por autor 


\section{Conclusiones}

El uso cotidiano de la imagen en la sociedad permite reflexionar sobre su utilidad en contextos educativos; su influencia y significado están presentes en las dinámicas e integraciones sociales dentro y fuera del aula. La cultura visual, como escenario de agencias y significación, presenta una oportunidad para atender los cambios generacionales que permitan transformar las estrategias pedagógicas para la enseñanza, pues, como afirma Castells, en la era de la información: "Las nuevas tecnologías de las comunicaciones en las dos últimas décadas han pasado por tres etapas diferenciadas: automatización de las tareas, experimentación de los usos y reconfiguración de las aplicaciones" (2012, p. 58). Es en esta última etapa que se presenta la experimentación del meme como posibilidad a incorporar en la práctica docente, constituyéndose en bloques de la cultura educativa (Brodie, 1996) durante la cotidianidad de la enseñanza.

Una revisión de los tipos de memes creados hizo evidente el predominio de los Rage o Paint comic y el meme fotografía, constituyéndose como las expresiones predilectas para trabajar la imagen como herramienta creativa para el análisis y síntesis de los textos. Esto tiene correspondencia con lo planteado por Vera, al advertir que: "En efecto, el meme responde a una forma ideal de concebir el mundo; reír es mucho más significativo en la actualidad, en razón a que "la vida es demasiado corta para tomársela en serio" (2016, p. $3)$. Incorporar la emoción a la cotidianidad de la práctica docente permite, en este caso, vincular el humor como medio para trabajar la enseñanza en contextos digitales.
Finalmente, es necesario destacar que la pre-sente experiencia ratifica algunos principios del conectivismo, específicamente que: A) El aprendizaje y el conocimiento dependen de la diversidad de opiniones, pues las interacciones generadas en las redes sociales fueron un complemento para los espacios de la asignatura; y B) La habilidad de ver conexiones entre áreas, ideas y conceptos está presente en estrategias pedagógicas que vinculan modalidades mixtas (b-learning) para mejorar la enseñanza, porque reflexionar sobre la imagen y su posibilidad pedagógica en la enseñanza presenta un camino para la mediación tecnológica.

Figura 6. Memes creados durante la experiencia
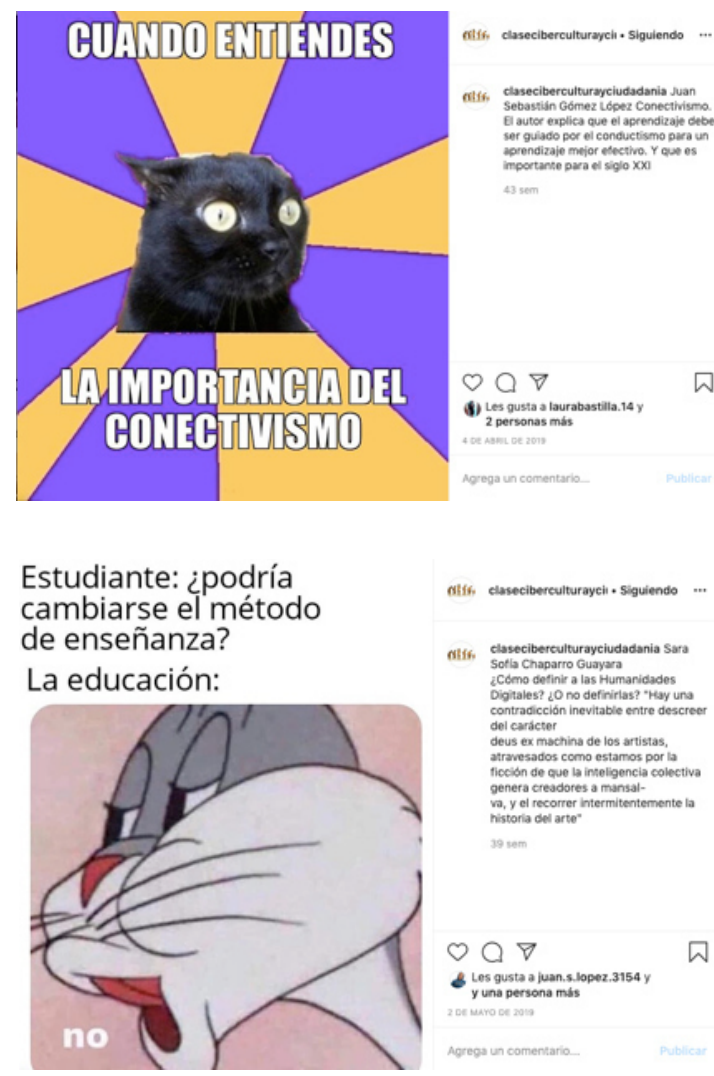


\section{Referencias}

Abril, G. (2013). Cultura visual, de la semiótica a la política. Madrid: Plaza y Valdés Editores.

Adar, E., Zhang, L., Adamic, L., y Lukose, R. (2004). Implicit structure and dynamics of blogspace. Draft research report for the HP Information Dynamics Lab. Obtenido desde hpl.hp.com/research/idl/ papers/blogs/index.html

American Antrophological Association. (1992). Anthropology and education quarterly. Obtenido desde https://www.americananthro.org/ StayInformed/Content.aspx? ItemNumber $=12836$

Artopoulos, A. (2011). La sociedad de las cuatro pantallas. Una mirada Latinoamericana. Barcelona: Ariel.

Barbero, M. (2009). Cuando la tecnología deja de ser una ayuda didáctica para convertirse en mediación cultural. Obtenido desde http://revistas.usal.es/ index.php/revistatesi/article/view/15549

Brodie, R. (1996). Virus of the mind: A new science of the meme. Seattle: Integral Press.

Campbell, L., Campbell, B., y Dickenson, D. (2002). Inteligencias múltiples. Usos prácticos para la enseñanza y el aprendizaje. Buenos Aires: Editorial Troquel.
Campos, L. (2012). Conectivismo como teoría de aprendizaje: conceptos, ideas, y posibles limitaciones. Revista educación y tecnología. Obtenido desde https://dialnet.unirioja.es/servlet/ articulo? codigo $=4169414$

Castells, M. (1999). La era de la información: economía, sociedad y cultura. La sociedad red. Madrid: Siglo XXI editores.

Castells, M. (2012). El impacto de Internet en la sociedad: Una perspectiva global. Obtenido desde http://bbvaopenmind.com

CEPAL. (2011). Aprender y enseñar con las tecnologías de la información y las comunicaciones en América Latina: potenciales beneficios. Santiago de Chile: CEPAL, División de desarrollo social.

Coll, C., Onrubia, J., y Mouri, T. (2007). Tecnología y prácticas pedagógicas: Las TIC como instrumentos de mediación de la actividad conjunta de profesores y estudiantes. Anuario Psicología, pp. 377-400.

DANE. (2017). Encuesta Nacional de Lectura. Obtenido desde https://www.dane.gov.co/index. php/estadisticas-por-tema/cultura/encuestanacional-de-lectura-enlec

Davison, P. (2005). The Language of Internet Memes. The Social Media Reader, pp. 120-134.

Dawkins, R. (1993). El gen egoísta. Barcelona: Salvat. 
Ferguson, K. (2013). Everything is a Remix. Obtenido desde https://www.everythingisaremix. info/watch-the-series

García, A. (2010). La Web 2.0: generador de un nuevo espacio educativo virtual. Trabajo presentado en el VII Congreso Internacional de Educación Superior, Febrero, La Habana.

García, F., y Gertrudix, M. (2011). Naturaleza y características de los servicios y los contenidos digitales abiertos. CIC. Cuadernos de Información y Comunicación, No. 16, 125-138. Obtenido el 4 de Julio de 2020 desde https://www.redalyc.org/ articulo.oa?id=935/93521629008 DOI: https:// doi.org/10.5209/rev_CIYC.2011.v16.7

García,I. (2013).Del memeal imeme, trascendiendo la dimensión lúdica. Revista Entretextos, Año, 5, No. 15.

Giesbrech, N. (2007). Connectivism: Teaching and learning. Obtenido el 26 de Marzo de 2008, desde http://design.test.olt.ubc.ca/Connectivism:_ Teaching_and_Learning

Guber, R. (2004). El salvaje metropolitano. Reconstrucción del conocimiento social en el trabajo de campo. Buenos Aires: Paidós.

Hall, S. (1997). Culture, media and identities. Representation: Cultural representations and signifying practices. Nueva York: Sage Publications, Open University Press.
Kaplún, G. (2005). Aprender y enseñar en tiempos de Internet. Formación profesional a distancia y nuevas tecnologías. Montevideo: CINTERFOR/OIT

Kaplún, M. (2014). Una pedagogía de la comunicación. Educommunication: Beyond 2.0. Sao Paulo: Paulinas.

Knobel, M. (2005). Memes and affinities: Cultural replication and literacy education. Miami: NRC. Obtenido desde http://everydayliteracies.net/ files/memes2.pdf

Lévy, P. (2004). Inteligencia colectiva. Washington: Organización Panamericana de la Salud. Obtenido desde http://inteligenciacolectiva. bvsalud.org

Mandiber, M. (2012). The language of internet memes. Obtenido desde http://spring2016. veryinteractive.net/content/6-library/7-languageof-internet-memes/language-of-internet-memes michaelmandiberg.pdf

Murray, S. (2008). Digital images, photo-sharing, and our shifting notions of everyday aesthetics. Journal of Visual Culture, 7(2), pp. 147-163. DOI: https://doi.org/10.1177/1470412908091935

Páramo, P. (2011). La investigación en ciencias sociales: estrategias de investigación. Bogotá: Universidad Piloto de Colombia.

Piscitelli, A. (2005). Internet, la imprenta del siglo XXI. Barcelona: Gedisa. 
Prensky, M. (2009). H. Sapiens Digital: From Digital Immigrants and Digital Natives to Digital Wisdom. Innovate: Journal of Online Education, Vol. 5, No. 3. Obtenido desde https://nsuworks.nova. edu/innovate/vol5/iss3/1

Prieto, E. (2008). El papel del profesorado en la actualidad. Su función docente y social. Redalyc. Foro de educación, Vol. 6, No. 10, pp. 325-345. Obtenido desde https://www.redalyc.org/ pdf/4475/447544585017.pdf

Rodríguez, S., Parra, M., Altarejos, M. (2001). Pensar la sociedad: Una iniciación a la sociología. Pamplona: Eunsa.

Runge, A. (2013). Didáctica: una introducción panorámica y comparada. Itinerario educativo, Año, XXVII, No. 62. DOI: https://doi. org/10.21500/01212753.1500

Scolari, C. (2013). Narrativas transmedia. Cuando todos los medios cuentan. Barcelona: Deusto Ediciones.

Siemens, G. (2004a). A learning theory for the digital age. Obtenido el 20 de Febrero de 2008 desde http://www.elearnspace.org/Articles/ connectivism.htm

Siemens, G. (2004b). Connectivism: a Learning Theory for the Digital Age. Obtenido el 22 de Marzo de 2011 desde http://www.elearnspace.org/ Articles/connectivism.htm
Soares, O. (2000). Educomunicação: um campo de mediações. Comunicação \& Educação, No. 19, pp. 12-24. DOI https://doi.org/10.11606/issn.23169125.v0i19p12-24

Soares, O. (2011). Educommunication: el concepto, el profesional, la aplicación: contribuciones a la reforma de la escuela secundaria. Sao Paulo: Paulina.

Vera, E. (2016). El meme como nexo entre el sistema educativo y el nativo digital: tres propuestas para la enseñanza de Lenguaje y Comunicación. Revista Educación y Tecnología, Año, 05, 8(2), pp. 1-15. Obtenido desde http://revistas.umce.cl/ index.php/edytec/article/viewFile/525/522

Vélez, J. (2012). Los memes de Internet y su papel en los medios de comunicación mexicanos. Memoria: XXIV Encuentro Nacional AMIC. Saltillo: UACoahuila. 